\title{
An Investigation into the Nature of the Oxide Layer Formed on Kovar (Fe-29Ni-17Co) Wires Following Oxidation in Air at 700 and $800{ }^{\circ} \mathrm{C}$
}

\author{
Paul M. Yates ${ }^{1}$ - Christopher F. Mallinson ${ }^{1}$. \\ Phillip M. Mallinson ${ }^{2}$ Mark J. Whiting ${ }^{1}$. \\ Julie A. Yeomans ${ }^{1}$
}

Received: 12 December 2016/Revised: 24 March 2017/Published online: 24 April 2017

(C) The Author(s) 2017. This article is an open access publication

\begin{abstract}
This work provides new insight and evidence that challenges and extends the accepted view of the oxidation behaviour of Kovar (ASTM-15). Specimens of $2 \mathrm{~mm}$ diameter Kovar wire were oxidised in air at 700 or $800{ }^{\circ} \mathrm{C}$ for $10 \mathrm{~min}$. The resulting oxide layers were analysed by X-ray diffraction, X-ray photoelectron spectroscopy, scanning electron microscopy with energy-dispersive X-ray spectroscopy, scanning transmission electron microscopy and Raman spectroscopy. Oxide layers of approximately 2 and $4 \mu \mathrm{m}$ thickness were formed at 700 and $800{ }^{\circ} \mathrm{C}$, respectively. These were found to contain iron, cobalt and traces of nickel. The combination of analysis techniques revealed that the oxide contains $\mathrm{Fe}_{2} \mathrm{O}_{3}$ in addition to $(\mathrm{Fe}, \mathrm{Co}, \mathrm{Ni})_{3} \mathrm{O}_{4}$, a spinel oxide, in contrast to the combinations of $\mathrm{Fe}_{3} \mathrm{O}_{4}$, $\mathrm{Fe}_{2} \mathrm{O}_{3}$ and $\mathrm{FeO}$ that are typically reported. The oxide layer was found to be complex, consisting of multiple layers with different compositions, which is overlooked in the existing literature.
\end{abstract}

Keywords Raman spectroscopy - Spinels · X-ray photoelectron spectroscopy (XPS) · Scanning electron microscopy (SEM) - Glass-to-metal seal

\section{Introduction}

The alloy Kovar, ASMT-15 (Fe-29 wt\% Ni-17 wt\% Co), is widely used in glassto-metal sealing because of its electrical properties and in particular its thermal expansion, which closely matches frequently used borosilicate glasses [1]. It has been common practice, for more than 60 years, to pre-oxidise Kovar prior to sealing

Mark J. Whiting

m.whiting@surrey.ac.uk

1 Department of Mechanical Engineering Sciences, The University of Surrey, Guildford, Surrey GU2 7XH, UK

2 Materials Science, AWE, Aldermaston, Reading RG7 4PR, UK 
to a glass so as to improve wetting and joining [1, 2]. However, the literature regarding the oxidation mechanisms and products is limited in its depth and is often contradictory.

Previous studies have used a range of oxidising atmospheres, such as air [3, 4], air in closed tubes [4], dry air [3, 5-7], purified air [8], steam and carbon dioxide [9] and nitrogen with water and hydrogen added [10]. The work presented here focuses solely on air as the oxidising atmosphere.

A range of oxides are reported in the literature, with some authors reporting various oxide layers composed only of iron oxides, for example $\mathrm{Fe}_{3} \mathrm{O}_{4}[9,11]$, $\mathrm{Fe}_{3} \mathrm{O}_{4}, \mathrm{Fe}_{2} \mathrm{O}_{3}$ and $\mathrm{FeO}$ [5] or $\mathrm{FeO}$ [3], whilst other authors report an oxide layer containing iron, cobalt and nickel in a spinel structure [8]. The composition of the oxide layer formed on Kovar is often assumed to be independent of oxidation temperature [11, 12], and a wide range of temperatures have been studied in the literature. There is, however, some evidence that the oxidation temperature affects the type of oxide formed [6-8].

Characterisation of the oxide is usually performed by X-ray diffraction (XRD) which has limited capabilities to differentiate between $\mathrm{Fe}_{3} \mathrm{O}_{4}$, a spinel, and other similar crystal structures that have also been proposed to be present in the oxide layer, such as $\mathrm{CoFe}_{2} \mathrm{O}_{4}$ which is also a spinel.

The presence of cobalt in the oxide may affect the bonding of Kovar to glass because of the differences in the solubility of cobalt as compared to iron in a glass or altered dissolution of iron from the $\mathrm{CoFe}_{2} \mathrm{O}_{4}$ spinel as opposed to $\mathrm{Fe}_{2} \mathrm{O}_{3}$. The presence, or absence, of $\mathrm{FeO}$ in the oxide layer and potential for dissolution of $\mathrm{FeO}$ into glass, may affect seal quality significantly because $\mathrm{FeO}$ is known to be a network modifier in glasses. Crystallisation characteristics of the glass may also be modified by dissolution of cations from the metal, which could be detrimental to the seal quality. This study aims to explore a specific oxidation treatment relevant to a common glass-to-metal seal and to characterise the oxide layer produced. The production of the particular seals is discussed further elsewhere [13].

\section{Experimental Procedures}

Since the purpose of this study was to understand the oxide on Kovar (ASTM-15), which was then going to be used in a glass-to-metal seal, the samples chosen for investigation were 2-mm-diameter wire (purchased from Testbourne Ltd), which was cut into straight $30 \mathrm{~mm}$ lengths, in the as-drawn state. In addition to these, Kovar (ASTM-15) plates were also analysed. These were purchased from Future Alloys as $50 \times 50 \times 2 \mathrm{~mm}$ sheets, which were polished using standard metallographic techniques to a $1-\mu \mathrm{m}$ diamond finish. All samples were cleaned using acetone and isopropyl alcohol prior to oxidation.

For oxidation, the samples were placed in preheated muffle furnaces for $10 \mathrm{~min}$, then removed and placed on an alumina block to air-cool. The wire samples were stood vertically so as to avoid damage to, or contamination of, the oxide. Some samples were prepared in cross section by standard metallographic methods. Thin 
foils were prepared using an FEI Nova Nanolab dual-beam FIB; standard lift out techniques were used.

Glancing incidence XRD (GIXRD) was performed using a PANalytical X'Pert Pro X-ray diffractometer with a $\mathrm{Cu} \mathrm{K} \alpha$ source.

X-ray photoelectron spectroscopy (XPS) was performed using a Thermo Scientific Theta Probe spectrometer, with a monochromated Al Ka X-ray source with a photon energy of $1486.68 \mathrm{eV}$. Samples were analysed with 400 - $\mu$ m-diameter beams and a beam power of $300 \mathrm{~W}$. Survey spectra and high-resolution spectra were acquired using pass energies of $300 \mathrm{eV}$ and $50 \mathrm{eV}$, respectively. All spectra were referenced to the aliphatic $\mathrm{C} 1 \mathrm{~s}$ photoelectron peak at $285.0 \mathrm{eV}$.

Scanning electron microscopy (SEM) and energy-dispersive X-ray spectroscopy (EDX) of the surfaces and cross sections were performed using a JEOL JSM-7100F with a Thermo Scientific Ultradry EDX detector. SEM and EDX were performed using a primary beam energy of $15 \mathrm{keV}$, a sample current of $27 \mathrm{nA}$ and a working distance of $10 \mathrm{~mm}$. The detector deadtime was typically $40-50 \%$ during analysis. EDX spectral imaging was performed to generate $256 \times 192$ pixel images, and the total live time was approximately $40 \mathrm{~min}$, producing a maximum count per pixel of between 500 and 1500 counts.

Scanning transmission electron microscopy (STEM) was performed using a Hitachi HD-2300A ultrathin film evaluation system, a dedicated STEM. Analysis was performed using a $200 \mathrm{kV}$ beam. EDX data were acquired with an EDAX silicon drift detector with a collection area of $10 \mathrm{~mm}^{2}$.

Raman spectroscopy was performed using a Renishaw Systems 2000 Raman Microscope equipped with a 20-mW, 514-nm argon ion laser. The standard operating power was reduced by $50 \%$ in order to reduce the chance of sample damage. Spectra were acquired using the Renishaw WiRE software, over a range of $2000-150 \mathrm{~cm}^{-1}$. Each spectrum was acquired for five 30 -second periods, per site, and combined to give average spectra.

\section{Results and Discussion}

Initially, the wires were examined visually and with SEM, to assess the adherence of the oxide, then mounted and cross-sectioned to measure the oxide thickness by SEM. The surface morphologies of the oxides on the plate and wire samples differ, as shown in Figs. 1 and 2. Whiskers were observed on the wires oxidised at both 700 and $800{ }^{\circ} \mathrm{C}$, as shown in Fig. 2. These are likely to arise because of compressive stresses generated in the growing oxide. Analysis by EDX showed that the whiskers were similar in composition to the surface of the oxide. They are unlikely to play a significant role in the glass-to-metal sealing process as they constitute only a small proportion of the surface oxide and will tend to be removed when glass is packed around the pin prior to sealing.

The oxide thicknesses on the wires were measured as approximately $(2.1 \pm 0.6)$ and $(4.0 \pm 0.2) \mu \mathrm{m}$, for the 700 and $800{ }^{\circ} \mathrm{C}$ oxides, respectively. These oxide thicknesses are at the lower end, or below, that is generally recommended for glassto-metal sealing with Kovar [3, 8, 11, 14, 15], yet the oxides formed at $800{ }^{\circ} \mathrm{C}$ still 

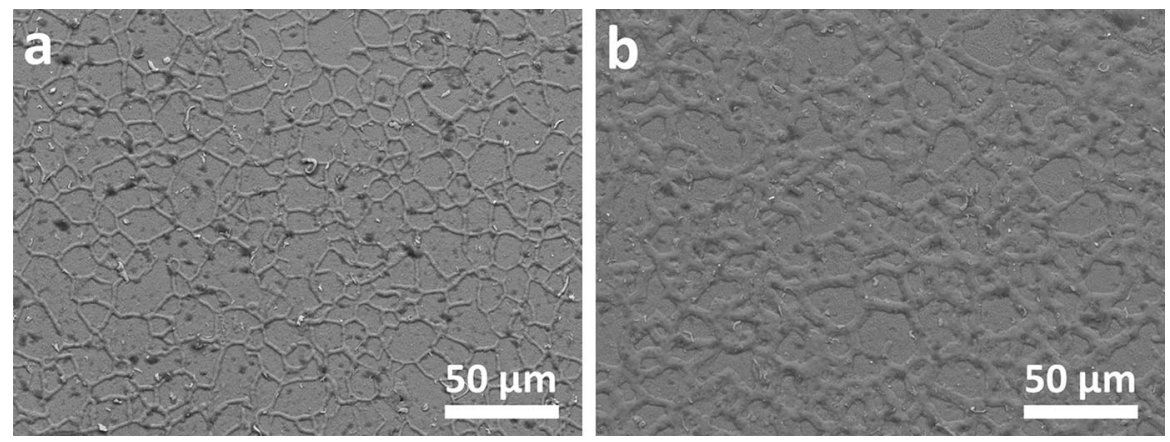

Fig. 1 Backscattered electron micrographs of Kovar plate oxidised at a $700{ }^{\circ} \mathrm{C}$ and $\mathbf{b} 800{ }^{\circ} \mathrm{C}$, showing the surface morphology resulting from the two oxidation temperatures

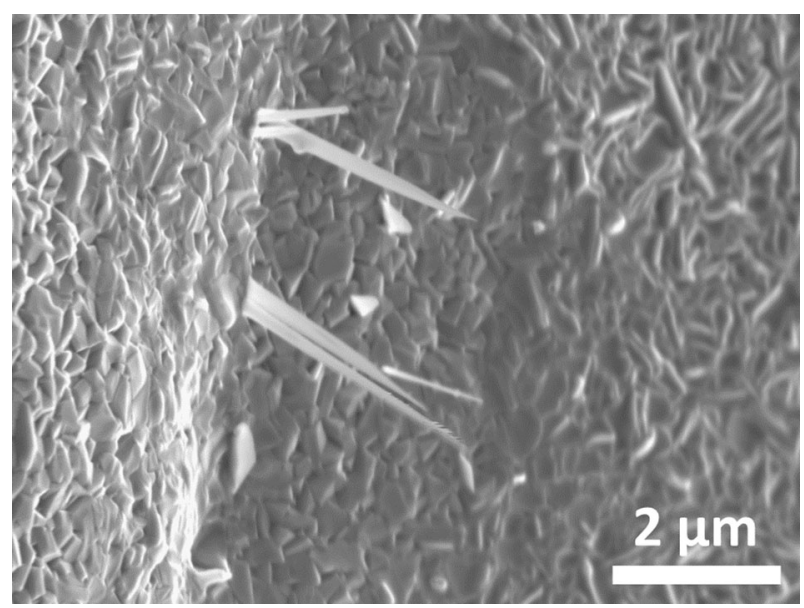

Fig. 2 Scanning electron secondary electron micrograph of the surface of Kovar wire oxidised at $800{ }^{\circ} \mathrm{C}$, showing the growth of whiskers from the oxide layer

show signs of poor adherence. The oxide on the $800{ }^{\circ} \mathrm{C}$ wire was easily dislodged if the sample was not treated with great care, whilst the $700{ }^{\circ} \mathrm{C}$ oxide could not be removed when the surface was abraded with a stainless steel scalpel, indicating better adherence. Spalling is observed in micrographs of the surface (Fig. 3) and in cross sections of wires mounted in resin (Fig. 4). Spalling is a result of the stresses built up in the oxide during growth.

Further characterisation of the Kovar wires was performed with XRD, since it is the standard approach used in the literature. XRD provided evidence of the presence of $\mathrm{Fe}_{2} \mathrm{O}_{3}$ and a spinel phase such as $\mathrm{Fe}_{3} \mathrm{O}_{4}$. As the wires are both rough and have a small radius, the XRD data acquired from them had a poor signal-to-noise ratio. As a result, it was decided to perform XRD on some flat polished Kovar plates, which provided improved XRD data. An example diffractogram is shown in Fig. 5 with the peaks for $\mathrm{Fe}_{2} \mathrm{O}_{3}$ and $\mathrm{Fe}_{3} \mathrm{O}_{4}$, labelled (the only two patterns that were indexed from the data). $\mathrm{Fe}_{2} \mathrm{O}_{3}$ and $\mathrm{Fe}_{3} \mathrm{O}_{4}$ were also indexed based on the data from the wire 

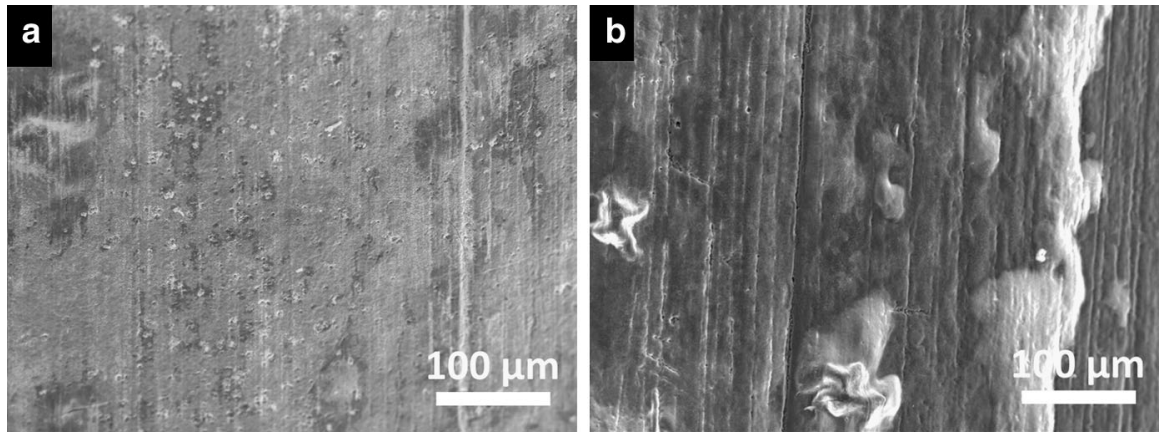

Fig. 3 Secondary electron micrograph of a a wire oxidised at $700{ }^{\circ} \mathrm{C}$, showing better oxide adherence and $\mathbf{b}$ a wire oxidised at $800{ }^{\circ} \mathrm{C}$, exhibiting spalling of the oxide and poor adherence

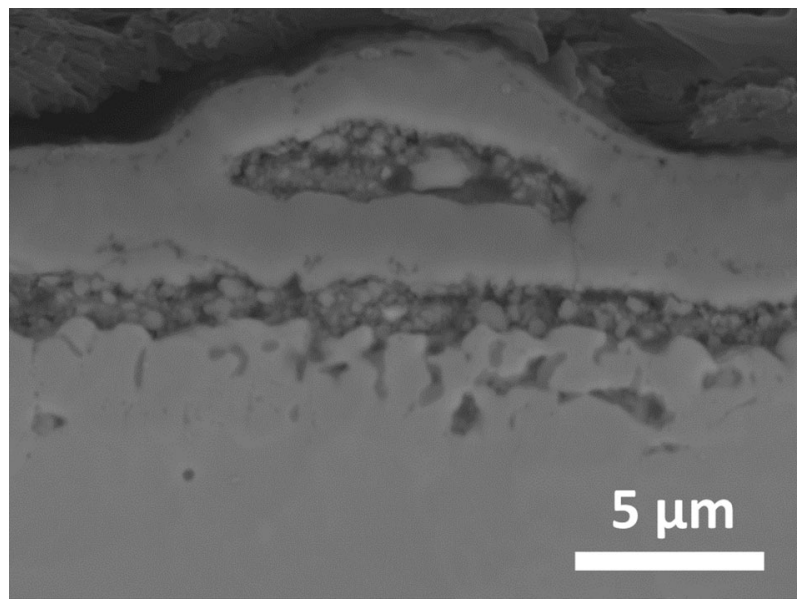

Fig. 4 Backscattered electron micrograph of a cross section of Kovar wire oxidised at $800{ }^{\circ} \mathrm{C}$; the oxide layer has buckled as a result of the stress within it

samples. Considering the XRD data in isolation would to lead to the conclusion that the oxides are $\mathrm{Fe}_{2} \mathrm{O}_{3}$ and $\mathrm{Fe}_{3} \mathrm{O}_{4}$. However, XPS analysis of the wire samples and the plate samples showed the presence of both iron and cobalt (as well as oxygen) at the surface of the oxide on the wires; the survey spectrum is shown in Fig. 6. The oxides on all of the samples showed the presence of $\mathrm{Fe}^{3+}$ and $\mathrm{Co}^{2+}$. The $\mathrm{Fe}^{2+}$ satellite was not observed, as shown in Fig. 7, indicating that $\mathrm{Fe}_{2} \mathrm{O}_{3}, \mathrm{CoFe}_{2} \mathrm{O}_{3}$ and $\mathrm{CoO}$ may be present in the upper layer of the oxide but that $\mathrm{Fe}_{3} \mathrm{O}_{4}$ is not. Elemental concentrations of the surface, from XPS, are given in Table 1. The depth of analysis for XRD is greater than the about $6 \mathrm{~nm}$ analysed by XPS, so it should not be assumed that $\mathrm{Fe}_{2} \mathrm{O}_{3}$ cannot exist deeper in the oxide.

The surface of the samples was covered with a significant amount of adventitious hydrocarbon contamination. As such, a correction was performed to provide an estimation for the elemental concentrations without the contamination, following a method from the literature [16]. The results from this correction result in 


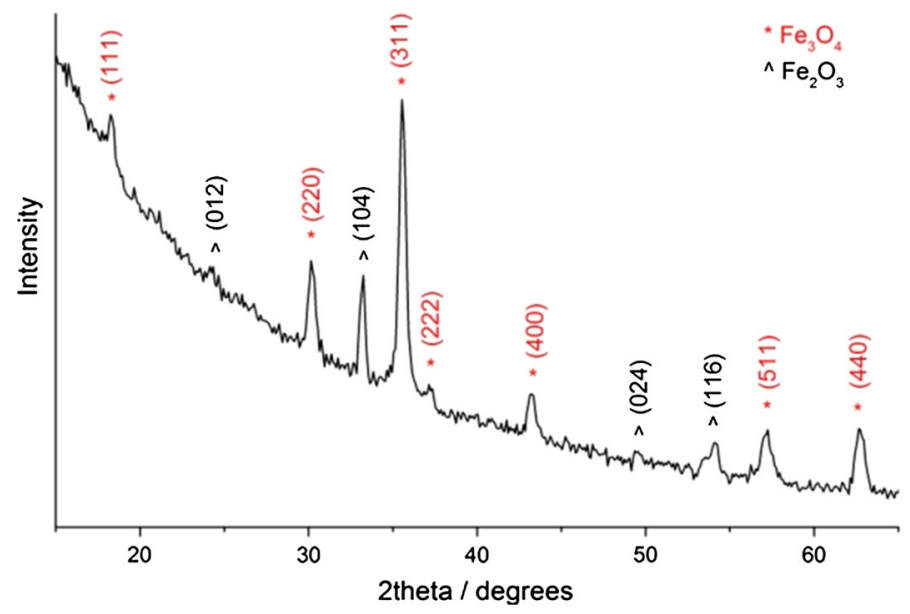

Fig. 5 GIXRD pattern from Kovar plate oxidised at $700{ }^{\circ} \mathrm{C}$ for $10 \mathrm{~min}$. The peaks can all be attributed to $\mathrm{Fe}_{2} \mathrm{O}_{3}$ or $\mathrm{Fe}_{3} \mathrm{O}_{4}$; this is not a definitive identification, since they cannot be distinguished from the peaks associated with other spinel structures such as $\mathrm{CoFe}_{2} \mathrm{O}_{4}$

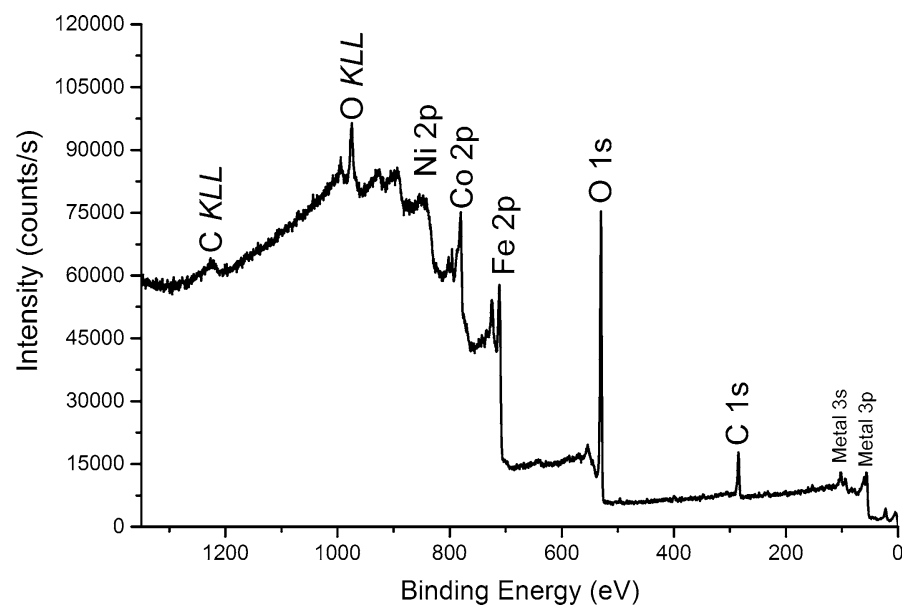

Fig. 6 XPS survey spectrum of Kovar plate oxidised at $800{ }^{\circ} \mathrm{C}$ for $10 \mathrm{~min}$

concentrations of $17.8,13.9$ and 2.8 at. $\%$ for $700{ }^{\circ} \mathrm{C}$, and $18.2,9.8$ and 1.0 at.\% for $800{ }^{\circ} \mathrm{C}$ for $\mathrm{Fe}, \mathrm{Co}$ and $\mathrm{Ni}$, respectively. It should be noted that prior to correction, the nickel concentration was $<0.5$ at. $\%$, considerably lower than the other two elements, resulting in the greatest error. A detailed evaluation of XPS spectra from Kovar plates, analysed using monochromated aluminium and achromatic magnesium X-ray sources, can be found elsewhere [17].

EDX analysis, including point spectra, line scans and elemental maps, was performed on polished cross sections of the oxides. The results showed a significant amount of cobalt and a small amount of nickel in the oxide layer. This is consistent 


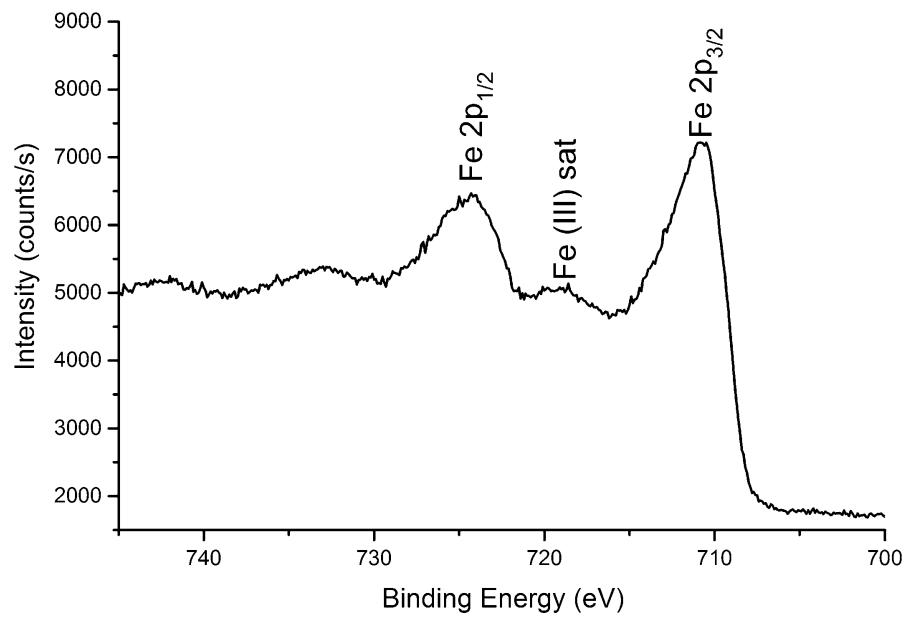

Fig. 7 High-resolution spectrum of the iron $2 \mathrm{p}$ region acquired from Kovar plate oxidised at $800{ }^{\circ} \mathrm{C}$ for $10 \mathrm{~min}$

Table 1 Atomic concentrations of species in the surface of the oxide, as measured by XPS, at. $\%$

\begin{tabular}{lcc}
\hline Element & $700{ }^{\circ} \mathrm{C}$ & $800{ }^{\circ} \mathrm{C}$ \\
\hline Iron & 18 & 21 \\
Cobalt & 8 & 10 \\
Oxygen & 46 & 48 \\
Carbon & 23 & 16 \\
\hline
\end{tabular}

with the XPS results which revealed cobalt to be present in the upper layer of the oxide.

There is significant overlap of the iron, nickel and cobalt $\mathrm{K} \alpha \mathrm{X}$-ray peaks in the EDX spectra of Kovar and its oxides reducing confidence in the EDX data. To mitigate this, phase analysis was performed using Thermo Scientific's COMPASS software. COMPASS data sets consist of full spectra at each pixel, rather than examining the number of counts in a predetermined region of interest assigned to an element. This ensures that there is no user bias in selecting elements and produces a probability map of identified components. COMPASS can spatially separate components with significant peak overlap and produce spectra for each component which can be quantified and compared with the other areas of the map. Wavelengthdispersive X-ray spectroscopy (WDX) is able to reduce the full width half maximum of the metal X-ray peaks to such an extent that the peaks no longer overlap in energy. As such, WDX mapping was also performed for iron, nickel, cobalt and oxygen to have complete confidence in their spatial distribution throughout the oxide layer. Although quantification of the WDX data was not performed, raw count maps agreed with the results from COMPASS, showing that there is an enrichment of cobalt at the surface of the oxide layer. 
Maps produced by COMPASS are shown for the 700 and $800{ }^{\circ} \mathrm{C}$ oxide layer in Figs. 8 and 9, respectively, and the resulting quantification from the maps is shown in Tables 2 and 3. They show that there is an enrichment of cobalt at the surface of
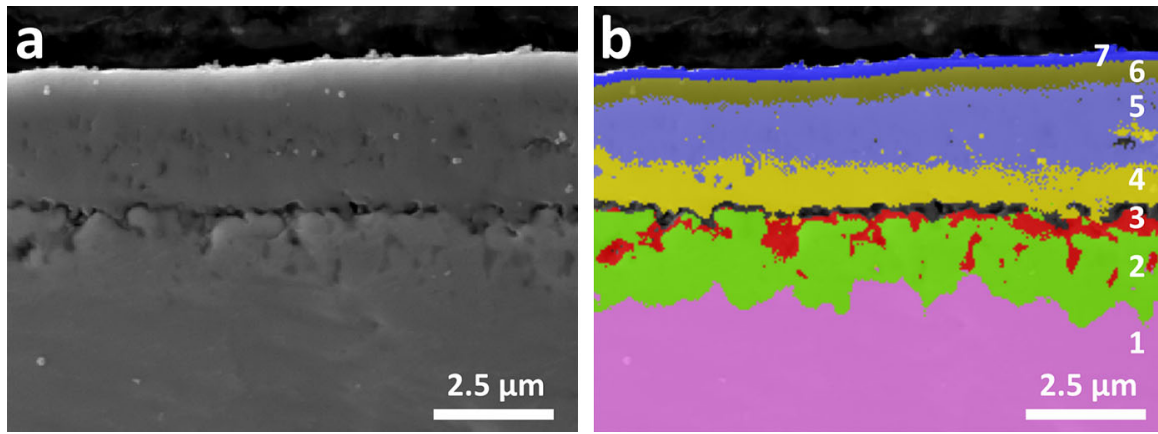

Fig. 8 a SEM micrograph of a cross section through the oxide formed on Kovar when oxidised at $700{ }^{\circ} \mathrm{C}$ for $10 \mathrm{~min}$ and $\mathbf{b}$ EDX map of the same site analysed by COMPASS to give quantifiable phase maps. The grey area at the top of the micrograph is the mounting material
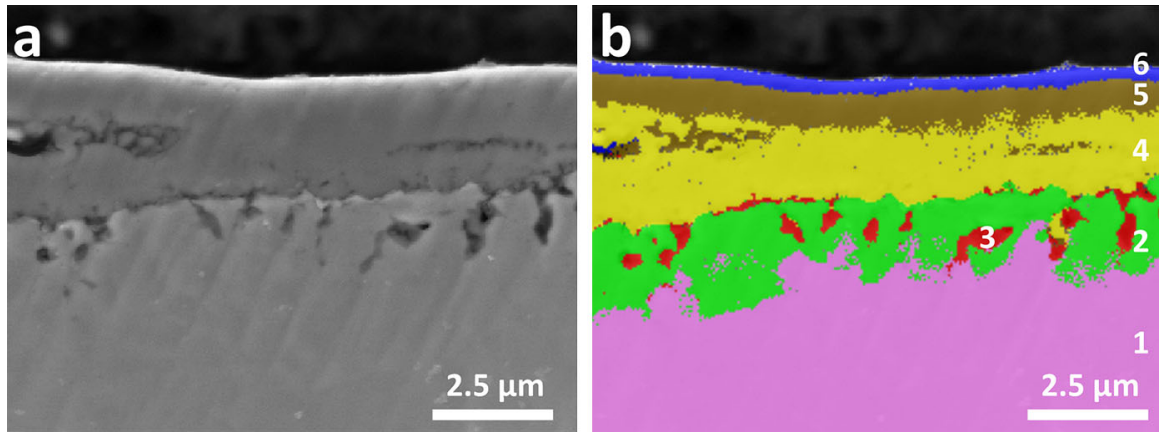

Fig. 9 a SEM micrograph of a cross section through the oxide formed on Kovar when oxidised at $800{ }^{\circ} \mathrm{C}$ for 10 min. b EDX map of the same site analysed COMPASS to give quantifiable phase maps. The grey area at the top of the micrograph is the mounting material

Table 2 Quantification data for the phases shown in Fig. 8, normalised at.\%

\begin{tabular}{lllllll}
\hline Phase & $\mathrm{O}$ & $\mathrm{Fe}$ & $\mathrm{Co}$ & $\mathrm{Ni}$ & $\mathrm{Ca}$ & $\mathrm{Au}$ \\
\hline Phase 1 (bulk) pink & - & 54 & 16 & 28 & 0.3 & 2 \\
Phase 2 (Fe-depleted layer) green & - & 31 & 20 & 47 & 0.4 & 2 \\
Phase 3 (porous inner layer) red & 25 & 49 & 10 & 14 & 0.5 & 1 \\
Phase 4 (bulk oxide layer) yellow & 39 & 49 & 9 & 2 & - & 1 \\
Phase 5 (Co, Ni poor oxide) purple & 40 & 49 & 8 & 1 & 0.5 & 1.5 \\
Phase 6 (iron-rich oxide layer) brown & 37 & 60 & - & 1 & 1 & 2 \\
Phase 7 (top layer) blue & 23 & 55 & 8 & - & 7 & 4 \\
\hline
\end{tabular}

Totals do not add to $100 \%$ because of a combination of rounding and some contaminants that are not included 
Table 3 Quantification data for the phases shown in Fig. 9, normalised at.\%

\begin{tabular}{llllll}
\hline Phase & $\mathrm{O}$ & $\mathrm{Fe}$ & $\mathrm{Co}$ & $\mathrm{Ni}$ & $\mathrm{Au}$ \\
\hline Phase 1 (bulk) pink & - & 52 & 17 & 27 & 1 \\
Phase 2 (Fe-depleted layer) green & 4 & 29 & 19 & 47 & 1 \\
Phase 3 (porous inner layer) red & 16 & 35 & 13 & 34 & 1 \\
Phase 4 (bulk oxide layer) yellow & 45 & 48 & - & 6 & 1 \\
Phase 5 (iron-rich oxide layer) brown & 32 & 66 & - & 1 & 1 \\
Phase 6 (top layer) blue & 7 & 74 & 17 & - & 2 \\
\hline
\end{tabular}

Totals do not add to $100 \%$ because of a combination of rounding and some contaminants that are not included

the oxide layers formed at both 700 and $800{ }^{\circ} \mathrm{C}$ with this region containing $>10$ at. $\%$ cobalt and little or no nickel. Below this, there is a layer which contains almost exclusively iron and oxygen, with $<1$ at. $\%$ nickel and no cobalt. This strongly indicates that the oxide layer is formed of more than one oxide. This layered morphology not only is consistent with the COMPASS analysis but is also observable in the SEM micrographs, with the top cobalt-rich layer being the most visible.

The degree of cobalt enrichment in the top layer seems to be greater in the oxide formed at $800{ }^{\circ} \mathrm{C}$ compared with the oxide formed at $700{ }^{\circ} \mathrm{C}$. Additionally, the width of the iron-rich layer below it is larger. However, the oxides seem to have similar structure and elemental composition within the individual layers.

All of the oxides have a high metal ( $\mathrm{Fe}, \mathrm{Co}, \mathrm{Ni}$ )-to-oxygen ratio (0.7-0.9) according to the COMPASS and EDX maps indicating that they are most likely to be $(\mathrm{Fe}, \mathrm{Co}, \mathrm{Ni})_{3} \mathrm{O}_{4}$ rather than $\mathrm{Fe}_{2} \mathrm{O}_{3}, \mathrm{FeO}$ or $\mathrm{CoO}$. However, it is expected that the oxygen will be under-accounted for in the quantification because the samples were gold-coated. This was necessary because even with carbon coating, there were signs

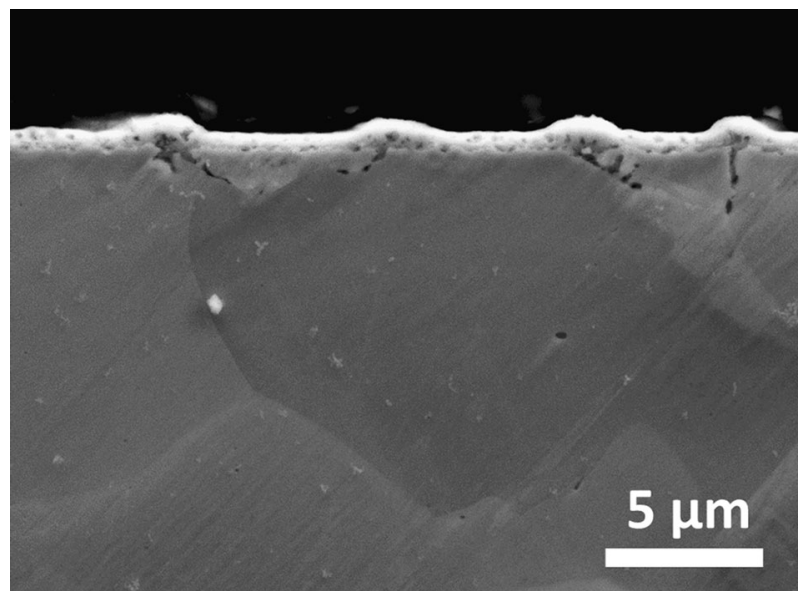

Fig. 10 SEM micrograph of a cross section of a Kovar plate oxidised at $700{ }^{\circ} \mathrm{C}$ showing porosity below the oxide layer along the grain boundaries 
of charging, leading to drift, which was unacceptable as it was necessary to acquire maps for more than a few minutes.

The iron-depleted region shown in the COMPASS maps is porous and, where grain boundaries are present, the porosity extends into the bulk metal along grain boundaries, as shown in Fig. 10. This is in agreement with the existing literature $[6,10,18,19]$. If the Kovar is to be used in a glass-to-metal seal, then the porosity may allow the molten glass to penetrate the metal leading to increased mechanical keying, improving the bond strength.
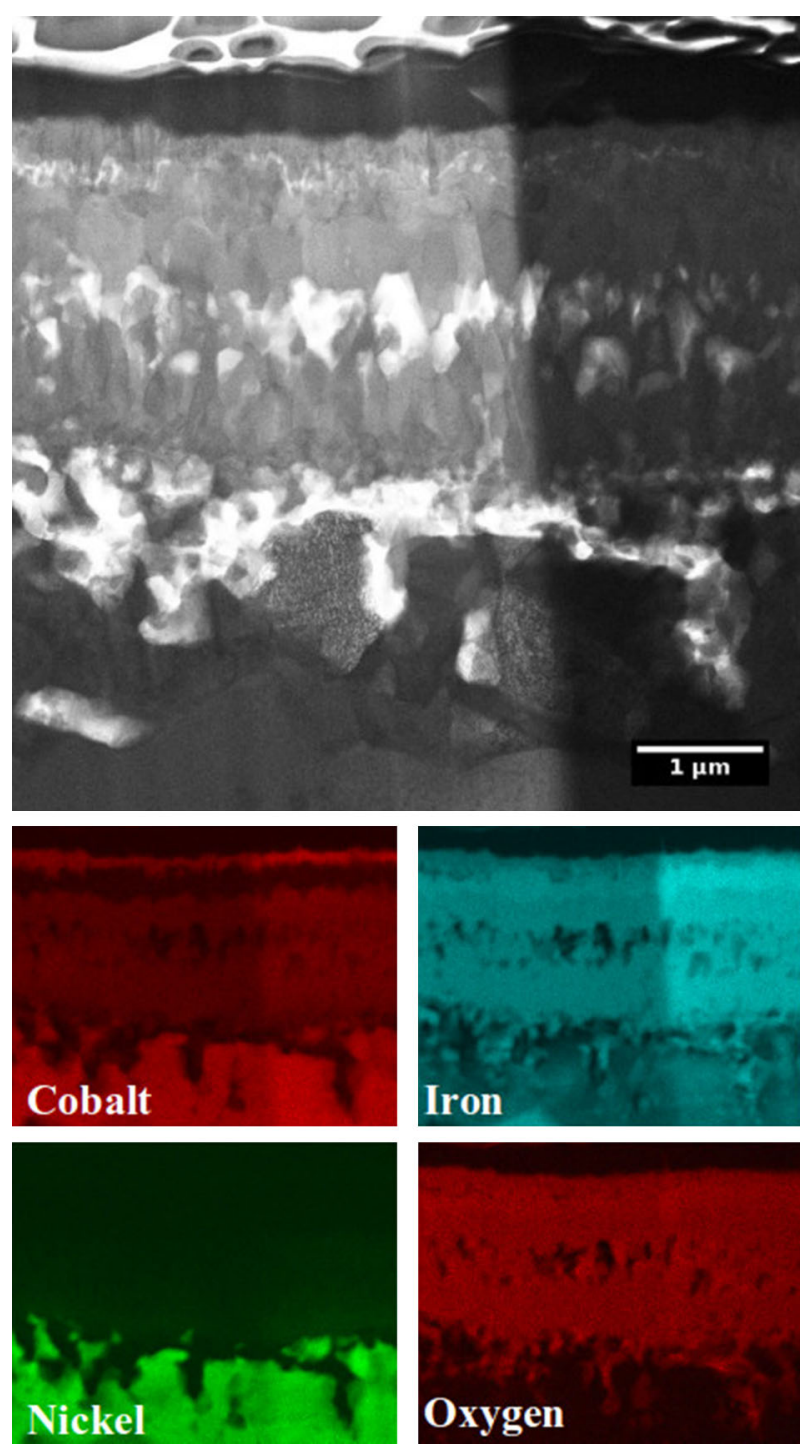

Fig. 11 STEM micrograph and EDX maps of the oxide layer formed on Kovar wire oxidised at $700{ }^{\circ} \mathrm{C}$. The four layers in the oxide can be seen 
The layered structure was confirmed by STEM, which has a much higher spatial resolution than the other techniques used. EDX maps shown in Fig. 11 show that the top layer of the oxide is enriched in cobalt, containing approximately 15 at.\% cobalt and no nickel; the layer below contains only iron and oxygen; the third layer contains iron, cobalt and oxygen; and the fourth layer also contains nickel.

The final technique used to characterise the oxide layer was Raman spectroscopy. This has previously been used to analyse $(\mathrm{Fe}, \mathrm{Ni}, \mathrm{Co})_{3} \mathrm{O}_{4}$ in nanoparticles [20, 22], thin films [23], and has been used to analyse corrosion of iron and steel [24-26]. However, it appears that Raman spectroscopy has not been used previously to characterise the oxide grown during the oxidation of Kovar.

Whilst the Raman spectra from $\mathrm{CoFe}_{2} \mathrm{O}_{4}$ and $\mathrm{NiFe}_{2} \mathrm{O}_{4}$ are similar, they are markedly different from the spectra of $\mathrm{Fe}_{3} \mathrm{O}_{4}$ and $\mathrm{Fe}_{2} \mathrm{O}_{3}$ and thus can be useful to differentiate between the different structures. $\mathrm{CoFe}_{2} \mathrm{O}_{4}$ has intense peaks around 470 and $695 \mathrm{~cm}^{-1}$ whilst $\mathrm{NiFe}_{2} \mathrm{O}_{4}$ has a similar spectrum with peaks at about 490 and $670 \mathrm{~cm}^{-1}$, which are not present in the $\mathrm{Fe}_{3} \mathrm{O}_{4}$ and $\mathrm{Fe}_{2} \mathrm{O}_{3}$ spectra. There is some variation within the literature of the exact peak position, but the main characteristic peaks have significantly different wavenumbers to any of the major peaks in the $\mathrm{Fe}_{3} \mathrm{O}_{4}$ and $\mathrm{Fe}_{2} \mathrm{O}_{3}$ spectra.

Raman spectra from Kovar pins oxidised at 700 and $800{ }^{\circ} \mathrm{C}$ are shown in Fig. 12. The spectra contain the characteristic peaks at about 470 and $695 \mathrm{~cm}^{-1}$ that are present in the $\mathrm{CoFe}_{2} \mathrm{O}_{4}$ spectrum. The other peaks in the observed spectrum can be attributed to the $\mathrm{Fe}_{2} \mathrm{O}_{3}$ Raman spectrum.

The spectra for the oxide formed at 700 and $800{ }^{\circ} \mathrm{C}$ show many similarities but are not identical. Some peaks that are associated with $\mathrm{Fe}_{2} \mathrm{O}_{3}$ are absent in the spectrum from the $800{ }^{\circ} \mathrm{C}$ oxide that are present in the $700{ }^{\circ} \mathrm{C}$ spectrum. This may be because the top layer of the oxide [thought to be $(\mathrm{Co}, \mathrm{Fe})_{3} \mathrm{O}_{4}$ ] is thicker in the oxide formed at $800{ }^{\circ} \mathrm{C}$ as compared with that formed at $700{ }^{\circ} \mathrm{C}$.

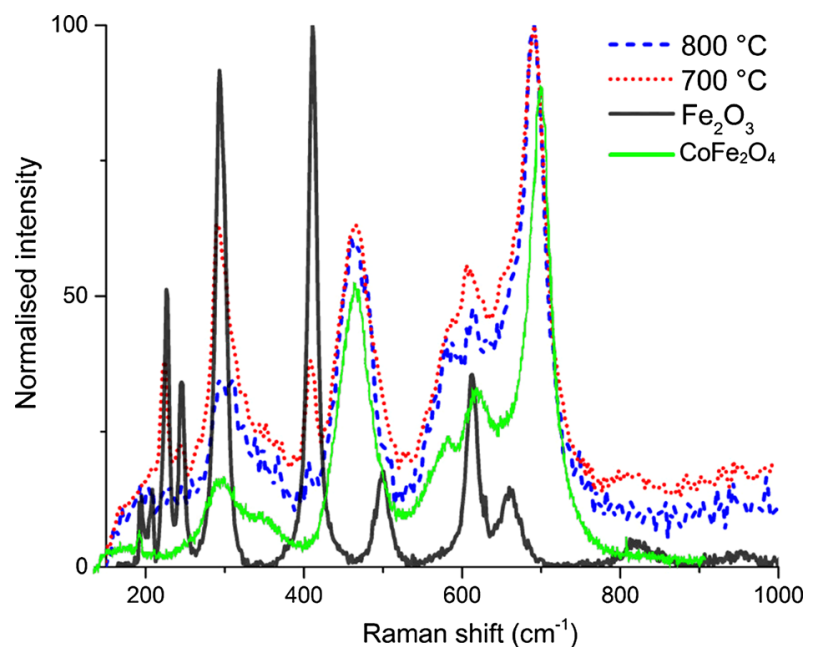

Fig. 12 Raman spectra from Kovar pins oxidised at 700 and $800{ }^{\circ} \mathrm{C}$ overlayed with spectra from $\mathrm{Fe}_{2} \mathrm{O}_{3}$ [21] and $\mathrm{CoFe}_{2} \mathrm{O}_{4}[22]$ 
The peaks at 224, 411 and $295 \mathrm{~cm}^{-1}$ (which are expected in the $\mathrm{CoFe}_{2} \mathrm{O}_{4}$ spectrum) are diminished in the $800{ }^{\circ} \mathrm{C}$ spectrum as compared to the $700{ }^{\circ} \mathrm{C}$ spectrum. In the $600-700 \mathrm{~cm}^{-1}$ region, there are a number of peaks; there is expected to be a shoulder at $624 \mathrm{~cm}^{-1}$ on the $695 \mathrm{~cm}^{-1} \mathrm{CoFe}_{2} \mathrm{O}_{4}$ peak but also a $\mathrm{Fe}_{2} \mathrm{O}_{3}$ peak at $614 \mathrm{~cm}^{-1}$; determining whether features in the experimental spectra belong to the $\mathrm{CoFe}_{3} \mathrm{O}_{4}$ or $\mathrm{Fe}_{2} \mathrm{O}_{3}$ spectra in this region is problematic. The peak at $500 \mathrm{~cm}^{-1}$, associated with the $\mathrm{Fe}_{2} \mathrm{O}_{3}$ spectrum, does not appear in the $700 \mathrm{~cm}^{-1}$ but appears as a small shoulder in the $800{ }^{\circ} \mathrm{C}$ spectrum.

The oxide layer that forms on Kovar when it is heated in air for $10 \mathrm{~min}$ at either 700 or $800{ }^{\circ} \mathrm{C}$ appears to be composed of the same phases; the oxide layer grown at $800{ }^{\circ} \mathrm{C}$ was thicker than the oxide layer grown at $700{ }^{\circ} \mathrm{C}((4.0 \pm 0.2)$ and $(2.1 \pm 0.6) \mu \mathrm{m}$ thick), respectively. The oxide has a layered structure which appears to consist of $(\mathrm{Co}, \mathrm{Fe}, \mathrm{Ni})_{3} \mathrm{O}_{4}$ with varying $\mathrm{Fe}: \mathrm{Co}$ :Ni ratios and $\mathrm{Fe}_{2} \mathrm{O}_{3}$. A schematic diagram of the oxide structure is shown in Fig. 13.

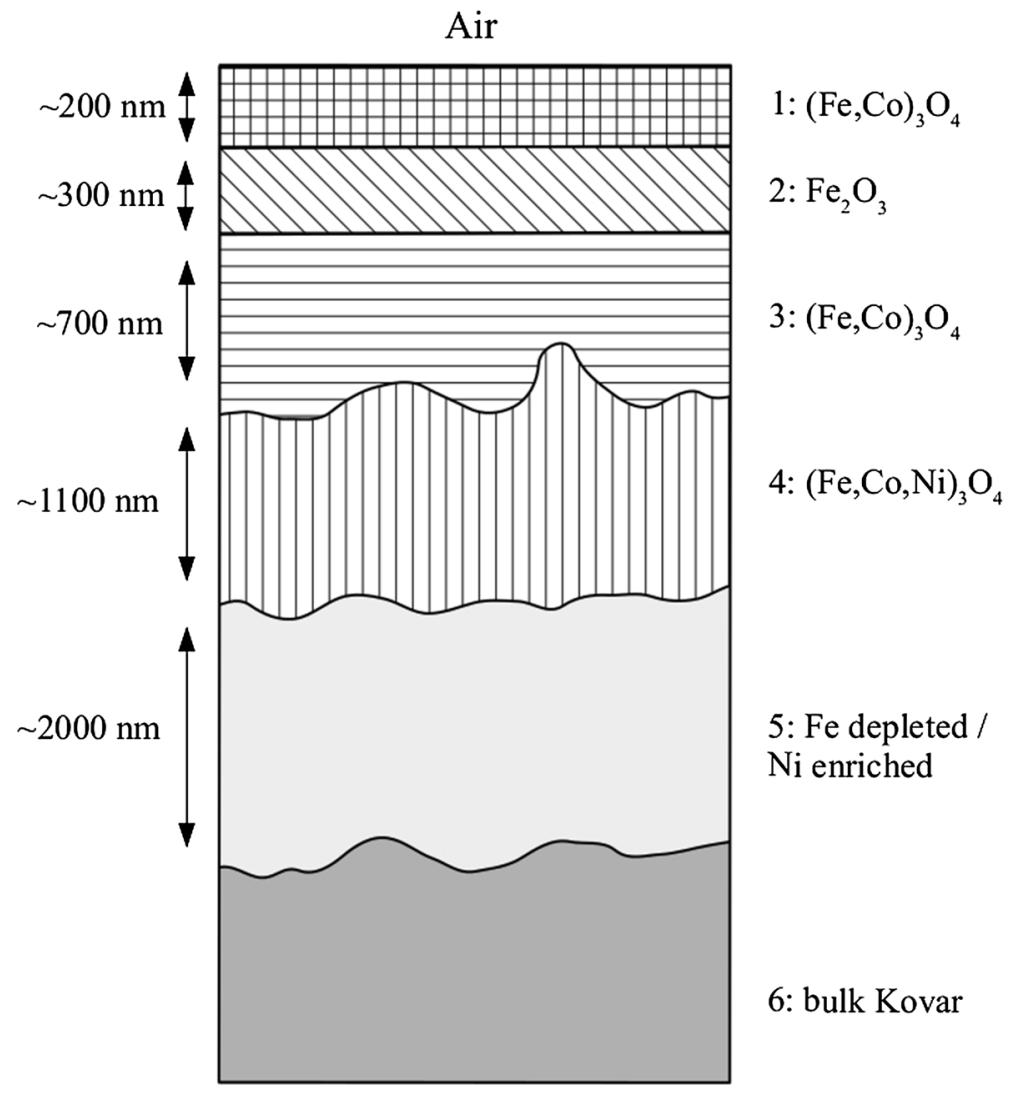

Fig. 13 The proposed structure of the oxide, with approximate thicknesses for the oxide grown at $700{ }^{\circ} \mathrm{C}$ 


\section{Summary and Conclusions}

The oxide formed on Kovar oxidised in air at 700 and $800{ }^{\circ} \mathrm{C}$ has been analysed and shown to be comprised of a layered structure with several different oxides, some of which have been previously overlooked in the literature. The top layer can be analysed by all of the techniques available in this study (XRD, XPS, SEM, STEM, Raman). Considering the evidence from all of the complementary techniques, it appears that this layer is $(\mathrm{Fe}, \mathrm{Co})_{3} \mathrm{O}_{4}$. XPS rules out the presence of $\mathrm{Fe}_{3} \mathrm{O}_{4}$ in this layer since only the $\mathrm{Fe}^{3+}$ satellite was detected, and not the $\mathrm{Fe}^{2+}$. EDX from STEM shows this layer to be 33 at.\% Fe, 15 at.\% Co and 39 at.\% O (with the remainder of the signal being from florescence from titanium and copper in the instrument and sample holder). This Fe:Co ratio (of 11:5) is close to the 2:1 ratio that would be found in $\mathrm{CoFe}_{2} \mathrm{O}_{4}$. The presence of the $\mathrm{CoFe}_{2} \mathrm{O}_{4}$ phase is further supported by the Raman spectroscopy, and it is also consistent with the XRD results (which was indexed initially as $\mathrm{Fe}_{3} \mathrm{O}_{4}$ but could also have been indexed as $\mathrm{CoFe}_{2} \mathrm{O}_{4}$ ).

The second layer cannot be analysed by XPS, but the other techniques (XRD, SEM, STEM, Raman) can still provide information. This layer is composed of an iron oxide, perhaps with a very small cobalt content, as shown by SEM and STEM. However, $\mathrm{FeO}$ was not detected by Raman spectroscopy or XRD (both of which would be expected to have an analysis depth that would include this layer since the top layer is only $\sim 200 \mathrm{~nm}$ thick). The EDX analysis of every layer in the oxide reveals less oxygen than would be expected; most analyses show more metal than oxygen. Thus, even though EDX gives a 1:1 ratio, it does not confirm that this layer is $\mathrm{FeO}$.

This layer has the lowest Fe: $\mathrm{O}$ ratio of all of the layers, suggesting that it is $\mathrm{Fe}_{2} \mathrm{O}_{3}$. If this layer is indeed $\mathrm{Fe}_{2} \mathrm{O}_{3}$ then this explains the results obtained by Raman spectroscopy and XRD, which both show $\mathrm{Fe}_{2} \mathrm{O}_{3}$ to be present. Since cobalt has no solubility in $\mathrm{Fe}_{2} \mathrm{O}_{3}$ [26], it is not surprising that this layer contains no cobalt.

The third layer can be analysed by SEM and STEM (including EDX and WDX). EDX, WDX and COMPASS maps all show that it contains both iron and cobalt, and oxygen, but no nickel. It is thought to be a $(\mathrm{Fe}, \mathrm{Co})_{3} \mathrm{O}_{4}$ spinel with varying cobalt content.

This fourth can also be analysed by SEM and STEM (including EDX and WDX). EDX, WDX and COMPASS maps all show that the composition appears very similar to the layer above it, but with the addition of around 3 at.\% nickel. It is thought to be a $(\mathrm{Fe}, \mathrm{Co}, \mathrm{Ni})_{3} \mathrm{O}_{4}$ spinel with varying cobalt and nickel content.

There is a region below the oxide that is depleted in iron and enriched in nickel and to a lesser extent cobalt. This is in agreement with the literature and is an expected result of the high iron content of the oxide layer (since the iron has diffused away from this region and into the oxide layer). The composition of this layer is approximately $45-50$ at.\% Ni, 25-30 at.\% Fe and 20-25 at.\% Co. Below the iron-depleted region is bulk Kovar. This proposed structure is consistent with all of the experimental data and was observed on multiple samples, but is in disagreement with the previous literature. 
Much of the literature on Kovar oxidation does not refer to the presence of cobalt in the oxide layer, probably as a result of an over-reliance on XRD for identification of the oxide. The presence of cobalt is important given the need in glass-to-metal sealing applications for the oxide layer to improve wetting and to dissolve into the glass. The oxide layer usually dissolves into the glass, and so the composition of the oxide will significantly affect the properties of the glass after sealing. For example, $\mathrm{FeO}$ is a network modifier and undesirable in the oxide formed for glass-to-metal sealing. The structure and properties of a sealing glass may be altered by the addition of cobalt from the dissolved oxide Kovar.

Acknowledgements The authors gratefully acknowledge support from Martyn Staff and James Castle for useful discussions. This work was supported by the Engineering and Physical Sciences Research Council (EPSRC) (Award EP/K503186/1) and AWE plc.

Open Access This article is distributed under the terms of the Creative Commons Attribution 4.0 International License (http://creativecommons.org/licenses/by/4.0/), which permits unrestricted use, distribution, and reproduction in any medium, provided you give appropriate credit to the original author(s) and the source, provide a link to the Creative Commons license, and indicate if changes were made.

\section{References}

1. I. W. Donald, Glass-to-Metal Seals (Society of Glass Technology, Sheffield, 2009).

2. J. H. Partridge, Glass-to-Metal Seals (Society of Glass Technology, Sheffield, 1949).

3. T.-S. Chern and H.-L. Tsai, Wetting and sealing of interface between 7056 Glass and Kovar alloy. Materials Chemistry and Physics 104, 472-478 (2007). doi:10.1016/j.matchemphys.2007.04.012.

4. A. Zanchetta, P. Lefort and E. Gabbay, Thermal expansion and adhesion of ceramic to metal sealings: Case of porcelain-kovar junctions. Journal of the European Ceramic Society 15, 233-238 (1995). doi:10.1016/0955-2219(95)93944-X.

5. C. Chanmuang, M. Naksata, T. Chairuangsri, H. Jain and C. E. Lyman, Microscopy and strength of borosilicate glass-to-Kovar alloy joints. Materials Science and Engineering: A 474, 218-224 (2008). doi:10.1016/j.msea.2007.04.016.

6. R. A. Piscitelli, S. K. Rhee and F. N. Bradley, Oxidation of Fe-29Ni-17Co Alloy. Journal of the Electrochemical Society 123, 929-933 (1976). doi:10.1149/1.2132970.

7. J. J. Stephens, F. A. Greulich, and L. C. Beavis, High Temperature Grain Growth and Oxidation of $\mathrm{Fe}-29 \mathrm{Ni}-17 \mathrm{Co}$ (kovar) Alloy Leads (Sandia National Labs., Albuquerque, NM (United States), 1993). http://www.osti.gov/scitech/biblio/10111396 (accessed March 18, 2016).

8. R. P. Abendroth, Oxide formation and adherence on an iron-cobalt-nickel glass sealing alloy. $M a-$ terials Research and Standards 5, 459-466 (1965).

9. I. E. Klein, A. E. Yaniv and J. Sharon, The oxidation mechanism of Fe-Ni-Co alloys. Oxidation of Metals 16, 99-106 (1981). doi:10.1007/BF00603746.

10. D. W. Luo and Z. S. Shen, Oxidation behavior of Kovar alloy in controlled atmosphere. Acta Metallurgica Sinica English Letters 21, 409-418 (2008). doi:10.1016/S1006-7191(09)60003-X.

11. J. A. Pask, New techniques in glass-to-metal sealing. Proceedings of the Institute of Radio Engineers 36, 286-289 (1948). doi:10.1109/JRPROC.1948.233914.

12. Carpenter Technology Corporation, Kovar Alloy Technical Data Sheet (1990). http://cartech.ides. com/datasheet.aspx?I=101\&TAB=DV_DS\&E=173\&SKEY=101.7.3310302\%3A7c523715-550b4445-9d27-1f06bdc35f6b\&CULTURE=en-US.

13. M. T. Staff, J. A. Fernie, P. M. Mallinson, M. J. Whiting and J. A. Yeomans, Fabrication of a glassceramic-to-metal seal between $\mathrm{Ti}-6 \mathrm{Al}-4 \mathrm{~V}$ and a strontium boroaluminate glass. International Journal of Applied Ceramic Technology 13, 956-965 (2016). doi:10.1111/ijac.12535. 
14. J. McCormick and L. Zakraysek, 17th Annual Reliability Physics Symposium, 1979 (1979), pp. 44-50. doi:10.1109/IRPS.1979.362870.

15. D. Lei, Z. Wang, J. Li, J. Li and Z. Wang, Experimental study of glass to metal seals for parabolic trough receivers. Renewable Energy 48, 85-91 (2012). doi:10.1016/j.renene.2012.04.033.

16. J. E. Castle, ISO/TEC TC 201/SC 3N Surface chemical analysis, Rules for identification of and correction for the presence of surface contamination.

17. C. F. Mallinson, S. Tardio, P. M. Yates, M. T. Staff, J. A. Fernie and J. F. Watts, XPS examination of the oxide layer formed on kovar following pre-oxidation. Surface Science Spectra 22, 58-70 (2015). doi:10.1116/11.20150301.

18. B.-S. Kim, Y.-G. Kim, H.-W. Lee and W.-S. Chung, Kinetics of Fe-30\% Ni-12.5\% Co invar alloy during high temperature oxidation. Metals and Materials International 8, 367-373 (2002). doi:10. 1007/BF03186109.

19. V. Chapman, B. J. Welch and M. Skyllas-Kazacos, High temperature oxidation behaviour of Ni-FeCo anodes for aluminium electrolysis. Corrosion Science 53, 2815-2825 (2011). doi:10.1016/j. corsci.2011.05.018.

20. M. A. G. Soler, T. F. O. Melo, S. W. da Silva, E. C. D. Lima, A. C. M. Pimenta, V. K. Garg, A. C. Oliveira and P. C. Morais, Structural stability study of cobalt ferrite-based nanoparticle using micro Raman spectroscopy. Journal of Magnetism and Magnetic Materials 272-276 (Part 3), 2357-2358 (2004). doi:10.1016/j.jmmm.2003.12.582.

21. E. Schlepp, R050300_RRUFF database: Heamatite raman spectrum. Available: http://rru.info/ R050300.

22. P. Chandramohan, M. P. Srinivasan, S. Velmurugan and S. V. Narasimhan, Cation distribution and particle size effect on Raman spectrum of $\mathrm{CoFe}_{2} \mathrm{O}_{4}$. Journal of Solid State Chemistry 184, 89-96 (2011). doi:10.1016/j.jssc.2010.10.019.

23. N. Bahlawane, P. H. T. Ngamou, V. Vannier, T. Kottke, J. Heberle and K. Kohse-Höinghaus, Tailoring the properties and the reactivity of the spinel cobalt oxide. Physical Chemistry Chemical Physics 11, 9224 (2009). doi:10.1039/b910707j.

24. R. J. Thibeau, C. W. Brown and R. H. Heidersbach, Raman spectra of possible corrosion products of iron. Applied Spectroscopy 32, 532-535 (1978).

25. J. H. Kim and I. S. Hwang, Development of an in situ Raman spectroscopic system for surface oxide films on metals and alloys in high temperature water. Nuclear Engineering and Design 235, 1029-1040 (2005). doi:10.1016/j.nucengdes.2004.12.002.

26. J. E. Maslar, W. S. Hurst, W. J. Bowers and J. H. Hendricks, In situ Raman spectroscopic investigation of stainless steel hydrothermal corrosion. Corrosion Science 58, 739-747 (2002). doi:10.5006/ 1.3277656 . 